\title{
Editorial
}

\section{Occupational Health in the new NHS}

Occupational health services in the National Health Services (NHS) came late and still vary from district to district both in quantity and quality of service. From small beginnings, the provision of occupational health services has expanded and now every health district either has its own service or has hospitals within it with services of their own. Most of these services are nurse based, although few are nurse led; despite the cliché that occupational health is a team based endeavour, there seem to be few doctors who are not prepared to be leader of the team. Substantially more occupational health nurses than occupational physicians are found within the NHS, however, and the medical input is relatively small; most often provided by part time physicians, many of whom have no special training or qualification in occupational health. There are few consultants in occupational medicine within the NHS and fewer training posts and although agreement has been reached recently with the Department of Health to establish more posts of senior registrar, it is certain that there will never be enough training posts to ensure that each district has its own consultant.

One of the great drawbacks of occupational health in the NHS is the lack of uniformity either of provision of service or of the type of service which is offered. The staff may comprise a couple of nurses and a part time clinical assistant giving no more than the most basic care up to a few large units employing several nurses, a consultant and other physicians (perhaps including a trainee), an occupational hygienist, staff counsellors, and other specialists brought in on an ad hoc basis. There is presently no agreement on the basic requirements of an occupational health unit within the NHS and some attention to this is long overdue.

Similarly, there is no uniformity of note keeping and not even any mechanism for the transfer of notes when a member of staff moves from one health district to another. It is quite likely, for example, that when a nurse moves to another hospital she will be treated as a new employee and asked to complete a preemployment questionnaire (which she will already have done at least once before). She may have to attend for (another) health assessment, she may well be required to submit to another Heaf test and a blood test to establish her concentration of antibodies to hepatitis B (information already in the notes held by her previous employer), and she may be asked to have a chest radiograph (which not many of us would now advocate). ${ }^{1}$ Some units, of course, do better and try to get this information, but they may be in the minority. It must be a simple matter to devise a system whereby what one might call the non-sensitive parts of employees' records travel with them from hospital to hospital.

Occupational health has never had a high profile within the NHS, probably because hospital doctors have seldom been caught in the net, at least not until some emergency has arisen such as a sharps injury. There have been a few opportunities to correct the balance and some time ago I suggested that the Control of Substances Hazardous to Health (COSHH) regulations could be used to make an impact even if the implementation of these regulations was not directly the responsibility of the occupational health staff. ${ }^{2}$

What will be the impact of the new arrangements within the NHS? Occupational health services will be providers of a service for which it is likely that they will have to have a contract (or at least an agreement) with those units which they serve at present. They will also have to purchase some services in their own turn, particularly from pathology laboratories. There has been some confusion as to whether or not consultants would be allowed to take referrals of hospital staff from occupational physicians because many of the staff would not live within districts with whom their employing authority had a contract. I believe that agreement has been reached with most hospital managements that such referrals will be accepted, but referrals by occupational physicians outside the health service may not be; this is another story, however.

With the new commercial spirit rampant, occupational health services have been actively encouraged to take on work outside the NHS and some have been successful in securing contracts with, for example, local authorities and small businesses. Some occupational health services have welcomed this development whereas others have responded at best with a feeling of inevitability. It is certain that pressure will be applied to ensure that those who have no outside work at present get some, and that those with outside contracts get more. Some managers see income generation as tapping a large source of wealth outside the NHS; a view which in my mind is delusory. Others (and they are probably the 
majority) wish the occupational health services to become self financing so that the calls on their own budgets are thereby reduced. To some extent, working for bodies outside the NHS is desirable in that it can provide a different experience for the staff and help in career development. What is lacking, however, is any firm agreement as to what range of services it is reasonable to offer, and to what extent the provision of a service for outsiders will act to the detriment of the service for the staff of the NHS. Finally, and most importantly, no way exists as yet by which the quality of the given service can be audited.

My own view is that too heavy a reliance on outside contracts as a means of financing occupational health services will not act to benefit occupational health as a whole within the NHS. I firmly believe in unifying services and the Journal has advocated that the occupational health units within the NHS should form the basis for a national occupational health service. ${ }^{3}$ This prospect was always remote, but now seems illusory because we are already beginning to see the developments of rivalry between occupational health units as they compete to tender for outside work.

Another threat that I can foresee relates to the contracts between the occupational health service and its own units. Trust hospitals will not, of course, need to offer their occupational health contract to their own unit and some might even be pleased to separate themselves from it. If the contract is to be settled purely on the question of price, then it seems to me certain that quality will fall. Even if the contract is kept in house, cost cutting may well follow. For example if the occupational health service suggests that it might be able to provide a full range of services for (say) $£ 35$ per capita, it will not take long for a shrewd chief executive to ask what can be provided for $£ 20$. And unless and until the occupational health service can provide evidence to show that its full range of services confers some cash benefit on the hospital, it may be difficult to respond except by cutting something out. Of course it will be said that it is no bad thing for occupational health services to look at what they do and to audit themselves, but in general managers are unlikely to be impressed by process auditing; they are more likely to want evidence of a good (that is, profitable) outcome, and this is much more difficult to come by.
Finally, what will the role of the occupational physicians be in all this? Like most other doctors, they are split about the changes now taking place; some welcome them as they have awakened dormant entrepreneurial tendencies, others view them with some despondency. I suggest the end result will be to lessen the requirement for full time occupational physicians in the NHS. The trend in larger units is now towards health promotion and screening and fitness testing, all areas for which occupational physicians are generally not well trained. The traditional parts of the service, such as preemployment screening, assessment of fitness for work, or investigations of poor work performance can almost all be carried out by trained occupational health nurses with a minimum of medical intervention because relatively little diagnostic acumen is required and treatment is almost never entered into. Moreover, as Lee and Kloss have pointed out in another context, ${ }^{4}$ the trend among the regulators is for directives relating to occupational health which will leave little room for clinical discretion and which require little medical input. I can see that by the end of the decade the occupational health services within the NHS will be nurse based and nurse led; if other professionals are involved, they are much more likely to be counsellors of various persuasions than physicians and any medical input required will be provided by doctors on a sessional basis. From the management point of view this would be an entirely satisfactory outcome; the nurses would be able to provide the essentials of a much honed down service, which could be provided for a comparatively modest price.

If this seems too dismal a view of the future, I would be glad to be reassured by those who hold a more joyful prospect.

Editor

HA WALDRON

British Journal of Industrial Medicine

1 Lunn JA, Waldron HA. Concerning the carers. Occupational health for health care workers. London: Heineman, 1991.

2 Waldron HA. COSHH and the NHS. Br J Ind Med 1989; 46:753-4.

3 Editorial. Occupational health for health workers. $\mathrm{Br} J$ Ind Med 1988;45:137-8.

4 Lee WR, Kloos DM. Lead astray? Br J Ind Med 1991;48:362-4. 